\title{
The Impact of Parkinson's Disease and Chronic Stroke on Simple Multitasking Abilities
}

\author{
Anaiya Kaka
}

International Baccalaureate program at Cathedral and John Conon School, Mumbai

\author{
${ }^{*}$ Corresponding author \\ Anaiya Kaka, International Baccalaureate program at Cathedral and John \\ Conon School, Mumbai, E-mail: anaiya.kaka@gmail.com
}

Submitted: 06 Nov 2018; Accepted: 10 Nov 2018; Published: 15 Nov 2018

\begin{abstract}
It is hypothesised that Parkinson's disease and chronic strokes may interfere with patient's ability to multitask. The aim of the study is to explore the impact of chronic stroke or Parkinson's on simple multitasking abilities. Both diseases cause the inability to perform simple activities such as walking and mental mathematics simultaneously. In a controlled sample of 15 patients of Indian origin with either chronic stroke or Parkinson's disease it was observed that there was a significant deterioration in the ability to multitask (increase in time taken to multitask between Timed up and Go (TUG) and Dual Timed up and Go (Dual TUG) versus a normal control group). The study found that the average increase in time required to complete the tests was 49\% (for chronic stroke patients) and $36 \%$ (for patients with Parkinson's disease) as compared to a normal baseline of less than $10 \%$. In patients with chronic stroke or Parkinson's disease, special attention must be paid to these impairments as they significantly affect independent living.
\end{abstract}

\section{Introduction}

Currently there are more than 1 million cases of Parkinson's disease per year in India alone [1]. With expected increase of ageing in the population of India, the country will likely witness a significant increase in the incidence of Parkinson's disease as has been seen in other countries [1].

Worldwide, stroke is the most common cause of mortality after coronary artery disease [2]. It is also the most common cause of chronic adult disability [2]. The lifetime risk of a stroke after 55 years of age is 1 in 5 for women and 1 in 6 for men. More than four-fifth of all strokes occur in developing countries such as India [2]. Strokes are one of the leading cause of functional impairments, with $20 \%$ of survivors requiring institutional care after 3 months and $15 \%-30 \%$ being permanently disabled [3]. Both chronic stroke and Parkinson's disease reduce the quality of life of the patients and cause them to be completely or partially dependant on others. At times, patients are able to perform motor tasks and cognitive tasks separately, but cannot perform dual tasks. This study is intended to assess the impact that these two disease have in carrying out simple and normal routines such as standing, walking and counting.

\section{Methodology}

This study was conducted at Sir H.N.Reliance Foundation Hospital in Mumbai in 2018 under the direction of Dr. Aashish Contractor and Dr. Poonam Bajaj. In this study, subjects who are of Indian origin and have been diagnosed with either chronic stroke for over 6 months or Parkinson's disease have been selected.
Patients were selected with the following criteria (Exhibits 1 and 2)

- Subjects must be diagnosed with Chronic Stroke or Parkinson's Disease without pre-existing cognitive impairment.

- Cognitive ability will be tested by the Mini-Mental State Examination(MMSE). Subjects must have a score higher than 22 out of 30 .

- Subjects must be able to ambulate independently with or without an assistive device

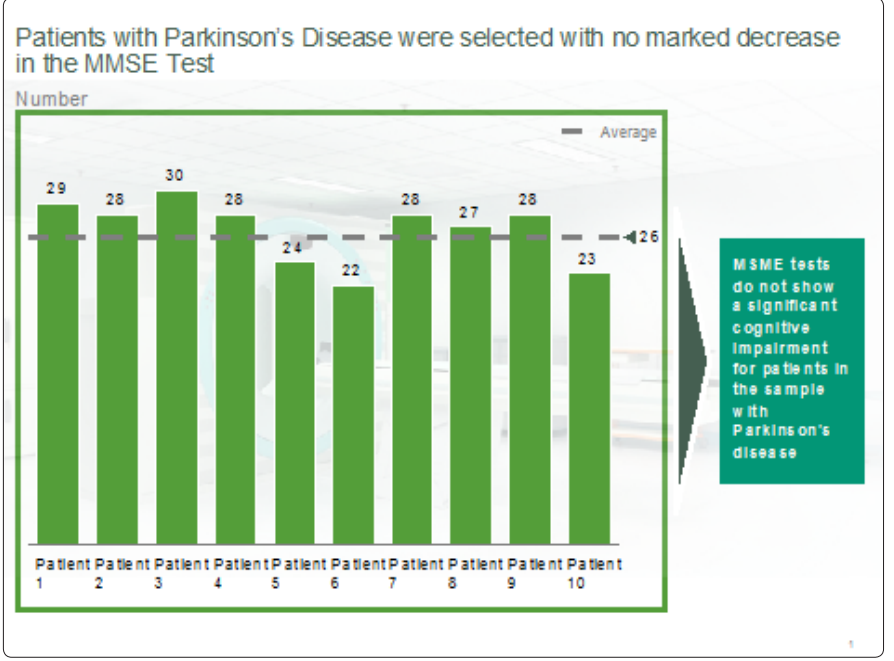


Patients with chronic stroke were selected that did not show a marked decrease in MMSE Test

Number

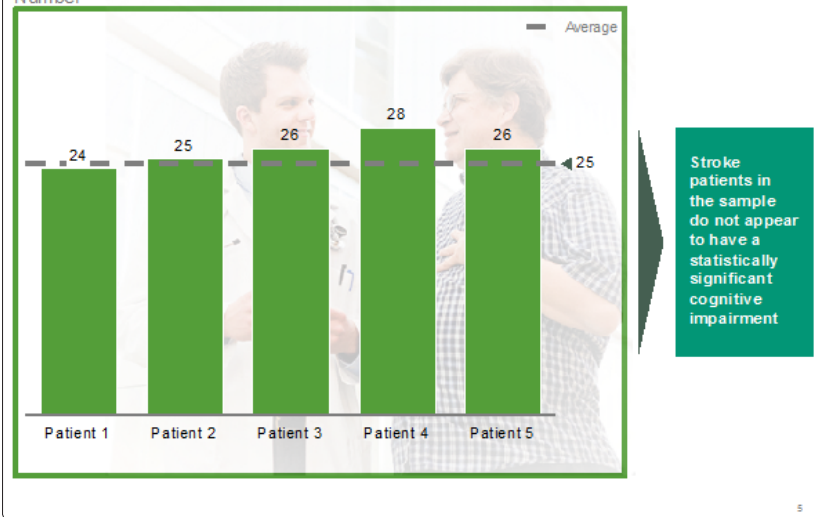

Patients that had additional ailments have been explicitly excluded from the study. Specifically:

- Subjects who are not independently ambulatory with or without an assistive device

- Subjects who have severe cognitive impairment with scores of below 22 on 30 on the Mini-Mental State Examination(MMSE) or

- Subjects who do not have either chronic stroke or Parkinson's disease.

Subjects will first take the MMSE test to check if they have any cognitive impairments. If they score above 22 , they then take the TUG test followed by the TUG with dual task test.

Timed Up and Go Test

The Timed Up and Go Test (TUG) assesses mobility, balance, walking ability, and fall risk in older adults.

\section{Equipment required}

Standard armchair (approximately $46 \mathrm{~cm}$ in height), stopwatch

Time to administer

Less than 3 minutes

\section{Required training}

No training required

\section{Description}

- The subject sits in the chair with his/her back against the chair back.

- $\quad$ Place a piece of tape or other marker on the floor 3 metres away from the chair so that it is easily seen by the subject

- On the command "go," the subject rises from the chair, walks 3 meters at a comfortable and safe pace, turns, walks back to the chair and sits down.

- Timing begins at the instruction "go" and stops when the patient is seatedagain.

- The subject can wear their regular footwear.

- There is no time limit. They may stop and rest (but not sit down) if they need to.

- The subject should have one practice trial that is not included in the score [4].
- Subject must use the same assistive device each time he/she is tested to be able to compare scores.

Cut-Off Scores indicating risk of falls by population (time in seconds)

$60-69$ years $>9.0[5]$

$70-79$ years $>10.2[5]$

$80+$ years $>11.3[5]$

Older stroke patients $>14$ [6]

Parkinson's disease $>11.5[7]$

Timed Up and Go with Dual Tasking test (adapted from the mini BEST test) Description

- The subject sits in the chair with his/her back against the chair back.

- $\quad$ Place a piece of tape or other marker on the floor 3 metres away from the chair so that it is easily seen by the subject

- On the command "go," the subject rises from the chair, walks 3 meters at a comfortable and safe pace, turns, walks back to the chair and sits down. The subject must count backwards by threes starting at 100 and continue backwards the entire time.

- Timing begins at the instruction "go" and stops when the patient is seatedagain.

- The subject can wear their regular footwear.

- There is no time limit. They may stop and rest (but not sit down) if they need to.

- The subject should have one practice trial that is not included in the score [1]

\section{Statistics Methodology}

R2 is a statistical measure of how close the data are to the fitted regression line. It is also known as the coefficient of determination or simply as the explained variation/ total variation [8]. It is always between -1 and 1 . A coefficient of -1 shows that the model or equation explains none of the variability of the response data and therefore relationship between the two variables [9]. A coefficient of 1 shows that the model or equation explains all the variability of the response data around its mean. In general the higher the R2 the better the model fits the data.

\section{Results}

This study shows that patients with chronic stroke or Parkinson's disease with no perceptible cognitive decline (as measured by the MSME test) do exhibit significant challenges in multitasking [10]. For example (as shown in Exhibit 3) the average increase in time for Dual TUG tests (as compared to standard TUG tests) was shown to be $36 \%$ in the case of Parkinson's disease and $49 \%$ in the case of chronic stroke. This compares with an average baseline of $<10 \%$ witnessed in normal patients for these tests [11]. (see table below11):

\begin{tabular}{|l|l|}
\hline Normal : & $\begin{array}{l}\text { There is no noticeable change in standing or walking } \\
\text { while counting when compared to TUG without dual task. }\end{array}$ \\
\hline Moderate: & $\begin{array}{l}\text { Dual task affects either counting or walking }(>10 \%) \text { when } \\
\text { compared to TUG without dual task }\end{array}$ \\
\hline Severe: & $\begin{array}{l}\text { Stops counting while walking or stops walking while } \\
\text { counting. }\end{array}$ \\
\hline
\end{tabular}




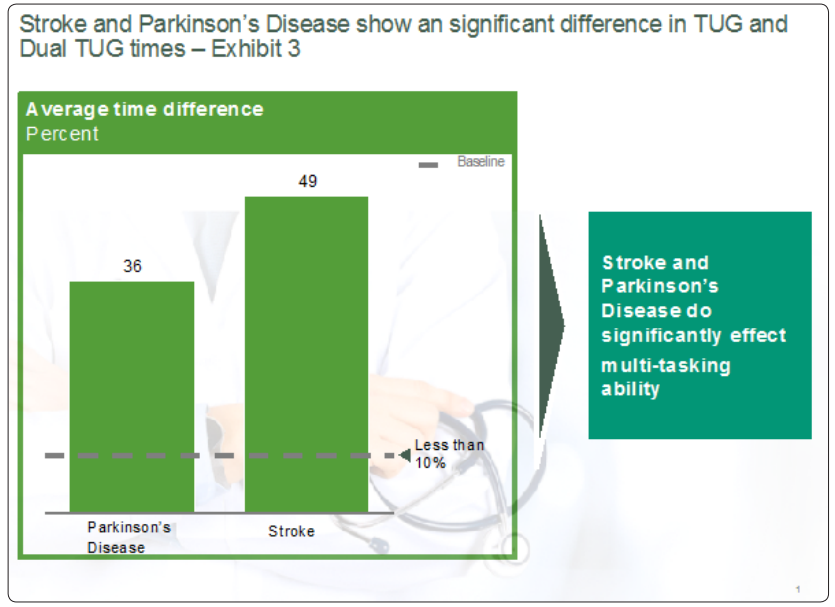

These changes were observed in a majority of the patients with consistently elevated times for the Dual TUG test (Exhibits 4 and 5 ). This was observed in all patients with the exception of a single chronic stroke patient that exhibited no significant change in times.
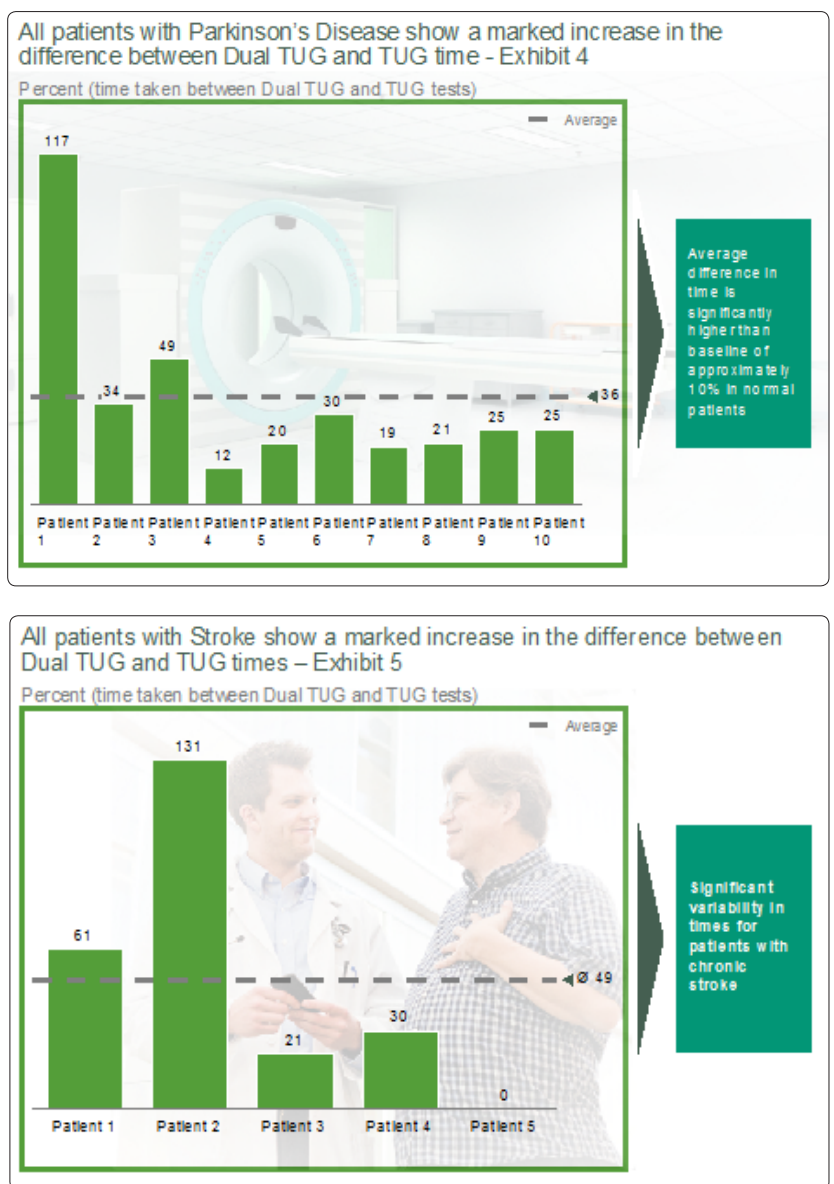

When plotted on an X-Y graph we see a distinct linear correlation between the TUG times and Dual TUG times. In virtually all cases we observe that the Dual TUG times are on average significantly longer indicating a challenge in multitasking abilities (Exhibit 6). The square of the Pearson product moment correlation coefficient between the two TUG times is 0.71 indicating a statistically significant relationship between the two times. In other words most patients with Parkinson's disease or chronic stroke will likely exhibit an increasing dual TUG time taken when compared to simple TUG times.

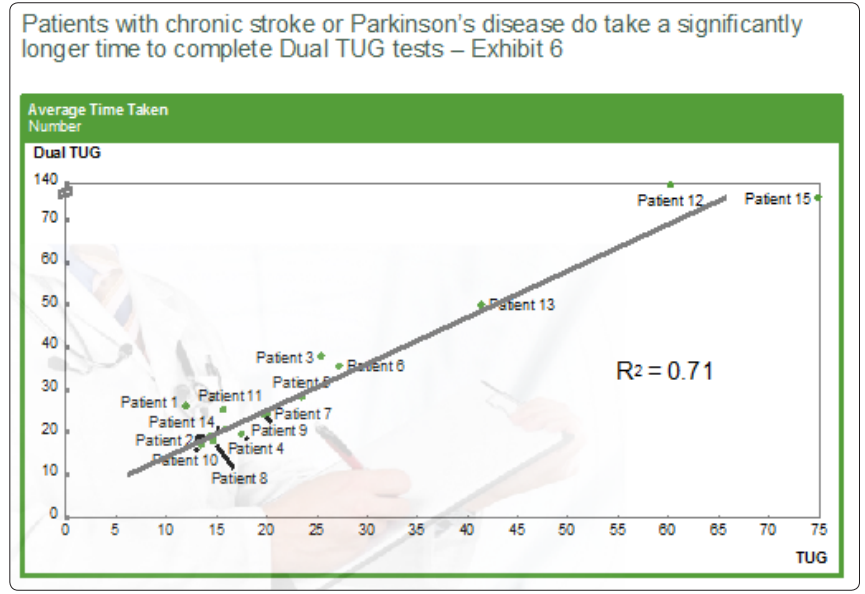

\section{Considerations}

There are several factors to be taken into account for this particular study:

- $\quad$ The TUG may demonstrate less reliability among patients suffering from cognitive impairment.

- Intrarater reliability may be affected by subject performance when completing multiple assessments indicating patients quickly become familiar with this test resulting in the first test affecting the second test [8].

- TUG was designed to be tested with people walking at a comfortable speed, yet at times is tested with the walking at a "quick yet safe speed".

- It is important that the chair is free standing, and not placed against a wall

\section{Conclusion}

This study effectively shows that TUG dual task scores are significantly higher than TUG scores in the chronic stroke and the Parkinson's disease population. This shows a definite involvement of attention to a supposedly automatic activity such as gait. Most people can walk and perform simple cognitive tasks at the same time such as talking, texting or performing simple calculations. However patients with chronic stroke or Parkinson's are not able to multi or even dual task. We may conclude from this that both Parkinson's disease and chronic stroke do significantly impair multitasking capabilities. Special care must be taken to improve the cortical attention of these patients given that this can significantly affect the ability to live independently. 
Fact Base

The full table of patient data is provided below for reference

\begin{tabular}{|c|c|c|c|c|c|c|c|c|c|c|c|c|c|c|c|}
\hline \multirow[b]{2}{*}{$\begin{array}{c}\text { Patient } \\
\text { No }\end{array}$} & \multirow[b]{2}{*}{ Age } & \multirow[b]{2}{*}{ Diagnosis } & \multicolumn{6}{|c|}{ MMSE Test } & \multicolumn{3}{|c|}{ TUG Test } & \multicolumn{3}{|c|}{ TUG test with Dual Task } & \multirow[b]{2}{*}{$\begin{array}{c}\text { Difference } \\
\text { between } \\
\text { TUG } \\
\text { tests (\%) }\end{array}$} \\
\hline & & & Orientation & Registration & $\begin{array}{c}\text { Attention } \\
\text { and } \\
\text { Calculation }\end{array}$ & Recall & $\begin{array}{c}\text { Language } \\
\text { and } \\
\text { Praxis }\end{array}$ & $\begin{array}{c}\text { MMSE } \\
\text { Total }\end{array}$ & Time 1 & Time 2 & $\begin{array}{l}\text { Average } \\
\text { Time } \\
\text { Taken }\end{array}$ & Time 1 & Time 2 & $\begin{array}{c}\text { Average } \\
\text { time } \\
\text { taken }\end{array}$ & \\
\hline 1 & 63 & PD & 9 & 3 & 5 & 3 & 9 & 29 & 12.36 & 11.83 & 12.10 & 31.86 & 20.71 & 26.29 & $117 \%$ \\
\hline 2 & 65 & PD & 9 & 3 & 5 & 2 & 9 & 28 & 13.96 & 14.82 & 14.39 & 17.75 & 20.69 & 19.22 & $34 \%$ \\
\hline 3 & 67 & PD & 10 & 3 & 5 & 3 & 9 & 30 & 24.67 & 26.22 & 25.45 & 38.51 & 37.26 & 37.89 & $49 \%$ \\
\hline 4 & 70 & PD & 10 & 3 & 3 & 3 & 9 & 28 & 18.83 & 16.33 & 17.58 & 19.96 & 19.39 & 19.68 & $12 \%$ \\
\hline 5 & 76 & PD & 7 & 3 & 5 & 2 & 7 & 24 & 25.95 & 21.2 & 23.58 & 31.83 & 24.81 & 28.32 & $20 \%$ \\
\hline 6 & 81 & $\mathrm{PD}$ & 7 & 3 & 3 & 1 & 8 & 22 & 26.98 & 27.55 & 27.27 & 36.8 & 34.26 & 35.53 & $30 \%$ \\
\hline 7 & 81 & PD & 10 & 3 & 5 & 2 & 8 & 28 & 20.1 & 20.1 & 20.10 & 24 & 24 & 24.00 & $19 \%$ \\
\hline 8 & 83 & PD & 10 & 3 & 2 & 3 & 9 & 27 & 16.27 & 13.27 & 14.77 & 16.41 & 19.21 & 17.81 & $21 \%$ \\
\hline 9 & 84 & PD & 9 & 3 & 5 & 2 & 9 & 28 & 20.26 & 18.98 & 19.62 & 24.43 & 24.55 & 24.49 & $25 \%$ \\
\hline 10 & 65 & $\mathrm{PD}$ & 7 & 3 & 5 & 0 & 8 & 23 & 13 & 14.2 & 13.60 & 16 & 18.05 & 17.03 & $25 \%$ \\
\hline 11 & 24 & Stroke & 7 & 3 & 4 & 3 & 7 & 24 & 15.18 & 16.4 & 15.79 & 24.16 & 26.56 & 25.36 & $61 \%$ \\
\hline 12 & 60 & Stroke & 8 & 3 & 5 & 1 & 8 & 25 & 59.53 & 61.01 & 60.27 & 142.24 & 136.81 & 139.53 & $131 \%$ \\
\hline 13 & 63 & Stroke & 9 & 3 & 4 & 3 & 7 & 26 & 41.63 & 41.27 & 41.45 & 48.49 & 51.87 & 50.18 & $21 \%$ \\
\hline 14 & 73 & Stroke & 10 & 3 & 4 & 2 & 9 & 28 & 16.06 & 15.71 & 15.89 & 23.52 & 17.7 & 20.61 & $30 \%$ \\
\hline 15 & 78 & Stroke & 8 & 3 & 5 & 2 & 8 & 26 & 74.83 & 75.01 & 74.92 & 77.24 & 73.25 & 75.25 & $0 \%$ \\
\hline
\end{tabular}

\section{Acknowledgments}

I would like to extend my sincere appreciation to the following people without whom this study would not be possible.

Dr. Aashish Contractor for giving me the opportunity to conduct this study and for all his very valuable inputs.

Dr. Poonam Bajaj for her guidance, constant support and mentorship. All the doctors and physiotherapists at the neuro rehab centre who took out time from their busy schedules to guide and assist me.

Thank you very much for giving me this opportunity to work and learn.

\section{References}

1. Kumari Punam, Nalin Chaudhary (2017) "Epidemiology of Parkinson's Disease In South Central India - A Longitudinal Cohort Study". Oaji.Net 4(7): 8-17.

2. Andersson A G, Kamwendo K, Seiger A, Appelros P (2006) "How to Identify Potential Fallers in a Stroke Unit: Validity Indexes of 4 Test Methods." Advances in Pediatrics., U.S. National Library of Medicine 38(3): 186-191.

3. Kumar Suresh, Fiona Taylor (2012) "Stroke In India - FactSheet (Updated 2012)". Research Gate.

4. Podsiadlo D, S Richardson (1991) "The Timed 'Up \& Go': a Test of Basic Functional Mobility for Frail Elderly Persons." Advances in Pediatrics., U.S. National Library of Medicine 39(2): 142-148.

5. Bischoff H A, Stahelin HB, Urscheler N, Ehrsam R, Vonthein R, et al. (1999) "Muscle Strength in the Elderly: Its Relation to Vitamin D Metabolites." Advances in Pediatrics., U.S. National Library of Medicine 80(1): 54-58.

6. Andersson A G, Kamwendo K, Seiger A, Appelros P (2006) "How to Identify Potential Fallers in a Stroke Unit: Validity Indexes of 4 Test Methods." Advances in Pediatrics., U.S. National Library of Medicine 38(3): 186-191.
7. Nocera Joe R, Elizabeth L. Stegemöller, Irene A. Malaty, Michael S. Okun, Michael Marsiske, et al. (2013) "Using the Timed Up \& Go Test in a Clinical Setting to Predict Falling in Parkinson's Disease." Advances in Pediatrics., U.S. National Library of Medicine 34(7): 1300-1305.

8. Dass Gaurhari (2015) "Regression Analysis: How Do I Interpret R-Squared and Assess the Goodness-of-Fit?" LinkedIn.

9. Banerjee Tapas Kumar, Shyamal Kumar Das (2016) "Fifty Years of Stroke Researches in India." Fifty Years of Stroke Researches in India 19(1): 1-8.

10. Van H J, Wirz M, Dietz V (2005) “Assessing Walking Ability in Subjects with Spinal Cord Injury: Validity and Reliability of 3 Walking Tests." Advances in Pediatrics., U.S. National Library of Medicine 86(2): 190-196.

11. "Mini-BESTest (2005) Balance Evaluation Systems Test." MiniBESTest: Balance Evaluation Systems Test, Oregon Health \& Science University.

Copyright: (02018 Anaiya Kaka. This is an open-access article distributed under the terms of the Creative Commons Attribution License, which permits unrestricted use, distribution, and reproduction in any medium, provided the original author and source are credited. 